\title{
Condições sociais de emergência de um subcampo esportivo: o caso do parkour Social conditions of emergency of a sportive subfield: the case of parkour Condiciones sociales de emergencia de un subcampo deportivo: el caso del parkour
}

Alessandra Vieira Fernandes, Vinicius Machado de Oliveira, Giuliano Gomes de Assis Pimentel, Juliano de Souza Universidade Estadual de Maringá (Brasil)

Resumo: Esse artigo analisa a constituição histórica do subcampo esportivo do parkour sob a perspectiva teórica de Pierre Bourdieu. Remete-se à uma abordagem sociológica de caráter descritivo-analítico, cujo material empírico expressa-se na produção online dos praticantes. Em linhas gerais, o processo de desenvolvimento do parkour evidencia a influência da midiatização dos bens culturais e a incorporação de elementos da lógica esportiva que produziram transformações na estruturação da modalidade e no habitus dos agentes. O surgimento de instituições reguladoras, programas de profissionalização e competições introduziram e acentuaram uma distinção entre amadores e profissionais, configurando relações de poder no interior da prática.

Palavras-chave: Esportes. Institucionalização. Esportivização. Pierre Bourdieu.

\begin{abstract}
This article analyzes the historical constitution of the sports subfield of parkour under the theoretical perspective of Pierre Bourdieu. It refers to a sociological approach of a descriptive-analytical character, whose empirical material is expressed in the online production of practitioners. In general, the development process of parkour evidences the influence of the mediatization of cultural goods and the incorporation of elements of the sports logic that have produced transformations in the structure of the modality and in the habitus of the agents. The emergence of regulatory institutions, professionalization programs and competitions have introduced and accentuated a distinction between amateurs and professionals, configuring power relations within the practice.
\end{abstract}

Keywords: Sports. Institutionalization. Sportivization. Pierre Bourdieu.

Resumen: Este artículo analiza el desarrollo histórico del subcampo deportivo del parkour de acuerdo con la perspectiva teórica de Pierre Bourdieu. Se hace referencia a un enfoque sociológico de carácter descriptivo-analitico, cuyo material empírico se expresa en la producción online de los practicantes. En general, el proceso de desarrollo del parkour muestra la influencia de la cobertura mediática de los bienes culturales y la incorporación de elementos de la lógica de los deportes que produjeron cambios en la estructura de la modalidad y en el habitus de los agentes. La aparición de instituciones reguladoras, programas de formación profesional y competiciones, introdujeron y ampliaron la distinción entre los amateurs y profesionales, estableciendo relaciones de poder dentro de la práctica.

Palabras clave: Deportes. Institucionalización. Deportivización. Pierre Bourdieu.

\section{Introdução}

É no interior de um espaço próprio de lutas e disputas que a legitimidade das funções de determinadas práticas sociais pode ser conquistada. O esporte é um desses espaços que além então de contar com seu sistema de instituições e agentes, possui leis próprias que orientam e determinam seu funcionamento. Em outros termos, este campo, a propósito dos demais campos sociais, constitui um espaço estruturado «[...] de posições cujas propriedades dependem das posições nestes espaços, podendo ser analisadas independentemente das características de seus ocupantes» (Bourdieu, 1983, p. 89). Tal arranjo estrutural exerce, portanto, uma espécie de coerção sobre a vontade dos indivíduos, uma vez que é capaz de orientar práticas e representações por meio da relação de poder entre os agentes engajados na apropriação do capital específico - gradiente de poder que se acumula no contexto de determinadas relações sociais -, seja ele econômico, social, cultural ou simbólico (Bourdieu, 1990).

Disso decorre o entendimento de que o processo histórico de espetacularização e institucionalização de diferentes atividades motrizes prescreve a constituição de um espaço de lutas cada vez mais acirrado no interior do campo esportivo em virtude do processo de esportivização dos bens culturais na sociedade de consumo (Marchi-Júnior, 2004; Souza, 2010;

Fecha recepción: 31-01-20. Fecha de aceptación: 12-03-20

Vinicius Machado de Oliveira

oliveira_vm@hotmail.com
Origuela \& Silva, 2012; Souza \& Marchi-Júnior, 2017). Esse processo, conforme será discutido no decorrer do texto, pode ser verificado no desenvolvimento do parkour que, ao adotar elementos da lógica esportiva, emergiu como subcampo concorrente no interior do campo esportivo, condição que, por sinal, pode ser comprovada pela emergência das instituições de regulamentação da prática, dos programas de certificação e profissionalização e dos eventos competitivos e programas midiáticos que exploram e promovem sua espetacularização.

Nessa esteira, cabe inicialmente reconhecer que o parkour tem suas raízes no Método Natural de Educação Física desenvolvido por Georges Hébert (Leyden-Rotawisky, 2013; Chagas, Rojo \& Girardi, 2015; Fernandes \& Galvão, 2016), o qual ficou amplamente conhecido pelo popular lema «Etre fort pour être utile» (Ser forte para ser útil) (Jubé, 2019). Em linhas gerais, por via dessa filosofia, o oficial da marinha francesa desenvolveu e apresentou ao mundo o seu método natural de ginástica, que tinha como influência o estilo de vida adotado pelos povos nativos das regiões selvagens da França, em especial, da Martinica Francesa (Jubé \& Quitzau, 2019). Nas suas viagens na marinha, Hébert observou e percebeu que esses povos, tanto os homens como as mulheres, possuíam um excepcional condicionamento físico, produto, em grande medida, do hábito ativo dessas populações que estavam em constante movimentação no meio natural. Em outras palavras, Hébert notou que os «selvagens», como ele costumava se referir, 
possuíam um repertório de movimento amplo e harmônico (andar, correr, saltar, escalar, levantar, nadar, lançar, etc.) que garantia não só o vigor dos seus corpos como também a subsistência dos grupos (Jubé \& Dalben, 2017). Foi através dessas observações que o tenente George Hébert pôde elaborar o seu método de treinamento que, mais tarde, se manifestaria também no contexto urbano se traduzindo, de alguma forma, no que hoje entendemos como parkour.

Há também que se destacar que um dos principais nomes a encampar o movimento de tradução do método natural para as áreas urbanas foi David Belle que, em conjunto com um grupo de jovens, adaptou o método para os subúrbios parisienses de Lisses na década de 1980 (Gus, 2011; Lordêllo, 2011; Fernández-Rýo \& Suarez, 2014). O parkour como é denominado pode ser compreendido como uma manifestação da cultura de movimento e cuja finalidade compreende as possibilidades de movimentação ou percursos através de técnicas próprias de deslocamento e transposição de obstáculos em qualquer ambiente (Lordêllo, 2011; Perriére \& Belle, 2014; Thibault, 2014; Fernandes \& Galvão, 2016; Murillo, 2020). A palavra parkour foi derivada do termo francês «parcours» que designa percurso ou rota. Essa denominação foi atribuída em 1996 quando Belle vivenciou, como bombeiro, o método militar francês parcours du combatant (Lordêllo, 2011). Aos praticantes foram denominados os termos traceur ou tracer, no caso do sexo masculino, e traceuse, no caso do sexo feminino (Potter, 2019; Ugolotti, 2019).

Importa aqui ressaltar que a difusão da modalidade a ponto de se tornar uma prática distribuída globalmente entre diferentes grupos sociais, se beneficiou da participação dos praticantes em peças teatrais, vídeos na internet e programas de televisão, indicando uma lógica incipiente de espetacularização (Fernandes \& Galvão, 2016; Kidder, 2017; Raymen, 2019; Potter, 2019). Nesse percurso, inclusive, é que ao longo dos anos 1990, as técnicas e os fundamentos filosóficos da modalidade difundiram-se de forma bastante significativa pela Europa e pelos Estados Unidos (Lordêllo, 2011).

No Brasil, há fortes indícios de que o parkour tenha surgido em 2004 por meio da internet e de esforços de praticantes que viajaram para o exterior e conheceram a modalidade, propagando-a em diferentes regiões do país (Stramandinoli, Remonte \& Marchetti, 2012). Ademais, ao estabelecer uma relação do subcampo com o espaço das posições sociais, tal como sugere Bourdieu (1983), é possível conjecturar que os primeiros agentes a monopolizarem e disseminarem a prática do parkour no país, eram detentores de volume representativo de capitais econômico e cultural, tendo em vista que possuíam acesso a viagens e internet, condições restritas à população nacional de classe média alta nesse período.

Diante desse cenário, esse artigo objetiva apresentar e analisar a constituição histórica do subcampo do parkour por meio do processo de institucionalização e espetacularização da modalidade. Para isso, parte-se [1] do aporte teórico de Pierre Bourdieu e [2] elege-se uma abordagem sociológica de caráter descritivo-analítico, cujo material empírico expressa-se na produção online dos agentes do subcampo do parkour, mais especificamente nas publicações em websites (sites nacionais e internacionais de instituições, associações e federações ligadas ao parkour, bem como demais plataformas especializadas e aderentes à prática). Esses dados, tal como será demonstrado, remetem à institucionalização e à espetacularização da modalidade e, mais que isso, apontam que a dinâmica de constituição histórica do parkour - no que tange, sobretudo, à sua estrutura organizacional - se deu através da criação de programas de certificação, de associações, federações e academias, ao passo que sua oferta - a partir de uma lógica espetacularizada - se traduziu em eventos competitivos e em seus regulamentos.

\section{Agentes e estruturas do emergente subcampo do parkour}

A crescente midiatização dos bens culturais e sua articulação à lógica esportiva com todas suas normatizações e competições, produziu transformações decisivas no habitus dos praticantes de parkour e, portanto, na própria estruturação do referido subcampo. Algumas dessas modificações podem ter relação direta com ações protagonizadas no interior do campo midiático, a exemplo da divulgação do filme Rush Hour (2002), uma das primeiras representações do parkour na mídia, além dos projetos como Jump London (2003) e Jump Britain (2005), também tematizando diretamente essa atividade motriz. Além dessas inserções, o parkour foi divulgado ainda nos filmes Yamakasi (2001) dirigido por Luc Besson, $13^{\circ}$ Distrito $(2004$; 2014) com David Belle e 007 Cassino Royale (2006) com participação de Sebástien Foucan. Conforme asseguram Lebreton et al. (2010), a indústria de comunicação além de constituir um dos vetores da institucionalização e reconhecimento dessa prática, contribuiu para difundir os estilos da modalidade e, portanto, as formas de praticá-la.

Nesse sentido, é que interpretamos a ação da mídia na diferenciação entre o parkour e o freerunning. Tais modalidades, inicialmente associadas, acabaram muito provavelmente se separando em virtude de lutas por prestígio, reconhecimento e poder. O surgimento do freerunning, atribuído ao documentário Jump London (2003) com participação de Sébastien Foucan, passou a priorizar saltos de ginástica e elementos das artes marciais com vistas à impressionar $\mathrm{o}$ espectador em lógica oposta ao parkour que, a princípio, visava um uso mais eficiente do movimento e, portanto, menos hedonista e estético. Nesse contexto, inclusive, é que o produtor do referido documentário, Guillaume Pelletier,

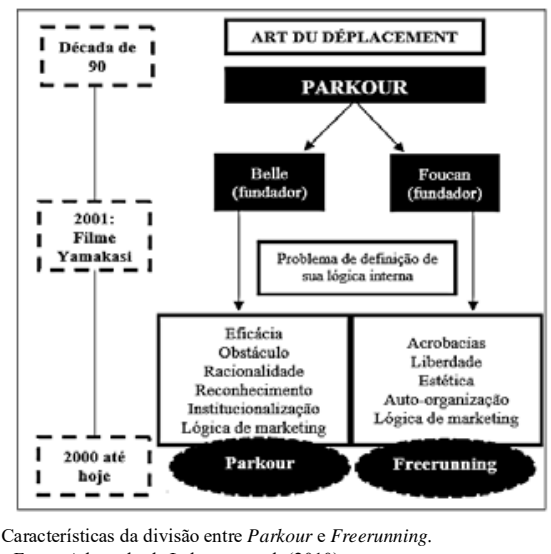

Fonte: Adaptado de Lebreton et al. (2010) 
sugeriu o nome freerunning (corrida livre) em detrimento ao termo parkour. Com o lançamento desse documentário, as diferenças entre as modalidades tornaram-se marcantes, conforme se expõe a seguir:

Como possível observar na figura 1, a divulgação do filme Yamakasi no ano de 2001, representa um ponto de inflexão importante na diferenciação entre parkour e freerunning, pois já aponta para concepções distintas de levar a efeito a prática da modalidade até então integrada, em um embate que se personificou nas figuras de David Belle e Sébastien Foucan, os dois principais franceses idealizadores do parkour. Cabe frisar que, nesse contexto, ambos os agentes já confrontavam suas perspectivas, porém o funcionamento distinto de tais práticas ainda não estava delineado, diferentemente do que ocorre nos dias atuais. De forma bastante sugestiva, a figura 1 ainda remete ao fato de que tanto o parkour quanto o freerunning estão integrados a uma lógica de mercado e de regulamentação de organização das práticas.

Avançando na composição deste cenário, Lordêllo (2011) sugere que o freerunning foi a contramedida através da qual grupos burgueses (que controlavam a modalidade) puderam - por via da mídia - espetacularizar e retirar o lucro que o parkour não possibilitara por sua filosofia se contrapor às apropriações e determinações do capital econômico. Todavia, antes do freerunning consolidar-se enquanto tal, Belle e outros agentes já estavam explorando e exibindo os movimentos do parkour em filmes de circulação mundial, o que contribuiu para o início da espetacularização da prática. Cabe também ressaltar que as características estéticas e exibicionistas do freerunning possibilitaram a espetacularização e a esportivização de ambas as modalidades, já que foram desenvolvidas em um percurso histórico paralelo.

Nesse processo de desenvolvimento relacional do parkour e do freerunning, a partir de 2005 foram fundadas, inclusive, organizações e instituições para direcionar e regulamentar o subcampo, contribuindo também para sua divulgação, expansão e profissionalização. A criação de programas de certificação de instrutores de parkour por essas organizações contribuiu para a distinção entre amadores e profissionais no interior do subcampo. Essa existência de um campo de produção especializado é, inclusive, condição do aparecimento de uma luta entre a ortodoxia e a heterodoxia (Bourdieu, 1989), ou seja, entre os dominantes (profissionais) e os dominados (amadores), o que, por conseguinte, configura-se como uma das condições de funcionamento do campo esportivo (Bourdieu, 1983,1990).

A primeira organização profissional de parkour do mundo foi criada em 2005, por membros da primeira e da segunda geração da modalidade, denominada de Parkour Generations (PKG) (Fernandes, 2018). A equipe da PKG contempla praticantes de diferentes países que atuam no ensino, consultoria, demonstrações públicas, representações artísticas, trabalho de mídia e pesquisas acadêmicas (Parkour Generations, 2020a). Essa equipe fundou o primeiro programa de qualificação de professores de parkour, o ADAPT (Art du Deplacement and Parkour Teaching). Esse programa foi oficializado a partir de uma demanda do governo britânico, tornando a certificação obrigatória para instrutores de parkour e para a fiscalização de políticas públicas direcionadas à modalidade na Inglaterra (Lordêllo, 2011).

O ADAPT é credenciado pelas instituições americanas National Academy of Sports Medicine (NASM) e Youth Sports Trust (YST) - responsáveis pela regulamentação da atividade física e esporte no país - e pela organização européia YMCAAwards que dirige a qualificação das ações de lazer e esporte. Esse programa de qualificação é considerado uma resposta à rápida expansão mundial do parkour, que direcionou as pessoas para uma prática insegura e sem preparação (ADAPT, 2020a).

A qualificação consiste, sobretudo, em um curso de formação que dura de três a cinco dias, baseado em avaliações que incluem testes físicos, escritos e verbais, assim como o registro de carga horária de treinamento supervisionado. $\mathrm{O}$ programa fomenta conhecimentos associados às técnicas dos movimentos de parkour e freerunning, habilidades de coaching e comunicação pedagógica, anatomia básica e fisiologia, prevenção e gestão de lesões e primeiros socorros (ADAPT, 2020a).

O programa contempla três níveis de qualificação. No nível 1, podem participar praticantes acima de 16 anos de idade e a certificação equivale à assistência técnica. $\mathrm{O}$ nível 2 certifica coach ou «treinadores» e podem candidatar-se praticantes acima de 18 anos de idade e com tempo de três a cinco anos de treino na modalidade. Nesse nível, o treinador é considerado capaz de ensinar os aspectos fundamentais da prática em qualquer situação e para qualquer pessoa. No nível 3, os candidatos precisam dispor mais de três anos de experiência no nível 2. Esse nível caracteriza-se pelo master coach, responsável por recrutar, supervisionar e desenvolver treinadores, assim como planejar e implantar ações de gestão e liderança. O ADAPT certificou mundialmente até hoje cerca de 549 instrutores de parkour, dos quais 19 são brasileiros e a maioria possui qualificação de nível 1 (ADAPT, 2020a).

Em 2005, também foi criada a American Parkour (APK), uma comunidade americana de parkour que atualmente oferece academias para a prática/ensino da modalidade e uma rede de mercado. Essa organização, por sua vez, construiu um sistema que certifica instrutores de parkour/ freerunning. Mais recentemente, a APK se inseriu em clubes universitários nos EUA e no Canadá a fim de associar capital cultural e simbólico à modalidade, pois, imersa em uma universidade, a organização percebia ser possível criar uma geração de praticantes assíduos e melhorar a imagem do parkour na visão do público (American Parkour, 2014). Já em 2007, foi fundada a World Freerunning and Parkour Federation (WFPF) que igualmente agrega um programa de certificação, no qual consta a qualificação de aproximadamente 600 especialistas na prática. O programa também consiste em três níveis de formação, assim como o ADAPT.

É importante nos atentarmos para o caráter ambíguo desses programas de certificação, pois se, por um lado, os mesmos qualificam praticantes para transmitirem os princípios e os movimentos fundamentais da modalidade com segurança e competência, por outro lado, acabam desqualificando aqueles agentes envolvidos (in)formalmente com a modalidade, mas que são destituídos de capital cultural em seu estado institucionalizado. Essa nova lógica, por sua vez, 
produziu, no interior do subcampo, relações de poder correspondente à estrutura de distribuição dos capitais econômico, cultural e simbólico, uma vez que esse sistema de qualificação permitiu separar «profissionais» de «amadores», ou seja, aqueles que possuem os recursos para investir na formação legítima e aqueles que não os possuem.

Não por acaso, é que essa ordem social de desigualdades precisa se justificar simbolicamente a partir de códigos de distinção naturalizados, os quais, por sua vez, só são possíveis porque os símbolos constituem sistemas performativos que funcionam como instrumentos de dominação (Souza, 2011; Souza \& Marchi-Júnior, 2017; Lasheras, et al., 2019; Rius \& Flix, 2019; Úbeda-Colomer, 2019). Conforme garante Bourdieu (1989, p. 11), «[...] os sistemas simbólicos contribuem para assegurar a dominação de uma classe sobre a outra». Nesse sentido, é possível dizer que a autonomia relativa do campo das práticas esportivas - e, no caso em tela, do parkour - garantida ao reconhecer aos grupos esportivos as faculdades de autoadministração e de regulamentação (Bourdieu, 1983), se beneficia desses sistemas simbólicos em sua lógica interna, reproduzindo assim na figura da luta entre amadores e profissionais a estrutura do campo do poder posta no espaço social mais amplo.

Ainda sobre as organizações que disputam o monopólio da gestão da modalidade, vale ressaltar que as mesmas têm se preocupado em desenvolver projetos voltados especificamente para as mulheres, o que configura uma possível demanda de ampliação ou visibilidade desse público no subcampo. A WFPF em resposta à demanda da audiência feminina, desenvolveu no ano de 2013 o projeto Lady WFPF Parkour administrado por mulheres para atender às necessidades de formação das praticantes da modalidade (WFPF, 2020a). Por sinal, em 2015, uma das atletas do Parkour Generations, Shirley Darlington-Rowat, foi responsável pelo projeto She Can Trace, que visa aumentar o público feminino praticante de parkour (Parkour Generations, 2020b). Ademais, a APK vem desenvolvendo «pontos de acesso» para as mulheres praticantes por meio de «encontros de mulheres» (American Parkour, 2020), em uma tentativa evidente não só de incluir esse público na prática, mas de expandir seu raio de ação mercadológica.

Já no que se refere ao direcionamento do parkour no Brasil, praticantes de diferentes regiões fundaram a Associação Brasileira de Parkour (ABPK), registrada em 2006 (Fernandes, 2018). AABPK é uma associação sem fins lucrativos, mas com fins simbólicos, criada para difundir a prática «correta» da modalidade. Essa associação promove anualmente o «Encontro Brasileiro de Parkour» que reúne praticantes de diversas regiões do país. A escolha anual da cidade sede do encontro é orientada por um edital divulgado pela associação.

Outra via importante de divulgação do parkour no Brasil tem sido efetivada na figura das academias especializadas que ofertam espaço para ensino/treino do parkour/ freerunning. Outro dado interessante é que apesar de ainda não existir um órgão nacional de certificação específico para a formação de instrutores no país, muitos praticantes possuem qualificação daADAPT ou da WFPF (ADAPT, 2020b; WFPF, 2020b). Além disso, algumas instituições exigem aos instrutores (sem essa certificação) o registro no Conselho
Federal de Educação Física, a fim de garantir a competência para fornecer aulas da modalidade.

\section{O avanço dalógica esportiva e a consolidação do subcampo}

Os primeiros e mais expressivos contornos espetaculares conferidos à modalidade de parkour se devem à sua crescente exposição na mídia e intensificaram-se com a expansão de eventos competitivos. Por sinal, a primeira competição da modalidade ocorreu em 2007 e, desde então, foram ampliadas, aperfeiçoadas e popularizadas em muitos países. Logo, a fase seminal do processo de espetacularização dessa atividade motriz pode ser atribuída ao evento competitivo Art of Motion, realizado pela empresa Red Bull (Aggerholm, Larsen, 2016).

Desde 2007, foram realizadas 17 edições do Art of Motion com predominância de realização em Santorini/Grécia (Fernandes, 2018). Até 2012, os atletas da competição eram recrutados por meio de «convites», ou seja, consistia em um evento restrito aos praticantes que detinham um capital simbólico e institucional no interior da modalidade. Posteriormente, os «convites» foram substituídos por uma qualificação online, cujos interessados no evento preenchiam um cadastro e submetiam um vídeo do YouTube (produzido exclusivamente para o evento) em uma plataforma de qualificação online (Fernandes, 2018). Essa qualificação caracterizava a primeira eliminatória da competição, na qual os praticantes com mais votos populares eram selecionados para uma qualificação local. Ademais, os desempenhos em edições anteriores qualificavam diretamente alguns atletas para a edição consecutiva.

A dinâmica das competições no Art of Motion abrangeu um percurso de obstáculos (estruturado pela organização do evento) em que os atletas tinham até 60 segundos para demostrarem suas habilidades, sendo julgados por critérios pré-estabelecidos, a saber, estilo, execução, dificuldade, fluidez e criatividade. Em todas as edições, os três participantes com melhores pontuações sagraram-se campeões e, em virtude disso, receberam premiações em dinheiro e patrocínios da empresa idealizadora. Além disso, o evento sempre procura oferecer também uma premiação (Best Trick) para o atleta que apresenta a melhor performance (Hagerty, 2016).

Com o relativo prestígio dessas edições do Art of Motion, outras empresas, academias e organizações perceberam a oportunidade de expandirem as competições no subcampo do parkour. Nesses eventos competitivos é possível observar que as regras específicas da modalidade foram construídas a partir das leis que regulamentam outros esportes radicais, remetendo, novamente, a uma intencionalidade de esportivização da prática.

Ainda nessa esteira, foram realizadas na cidade de Londres duas edições do Barclaycard World Freerun Championships (WFC) em 2008 e 2009. Tal evento, organizado pela companhia Freeflow Urban, contou com a presença de 25 atletas patrocinados pela empresa Barclaycard que competiram em uma estrutura planejada. Oportuno destacar que esse evento articulou elementos similares ao Art of Motion no tocante aos critérios de julgamento e à dinâmica de competição (World Freerun Association, 2014).

De forma semelhante, a organização Originis Parkour 
do Canadá desenvolve desde 2013 o North American Parkour Championships (NAPC), contemplando também, além da categoria para adultos, a categoria júnior (NAPC Júnior para crianças e adolescentes de 8 a 16 anos de idade). Essa competição, em ambas categorias, incluiu duas baterias de velocidade, dois testes de habilidades e um circuito de estilo livre em duplas (Hagerty, 2016). No NAPC Júnior, as rotas e os movimentos podem ser escolhidos individualmente, enquanto o NAPC contempla um percurso/rota determinado para os atletas.

Competições internacionais com bastante expressão foram também organizadas pela WFPF, que realizou eventos no México e na Espanha e, em 2016, promoveu um campeonato em Las Vegas com a maior premiação em dinheiro em relação às competições de Parkour, até onde se tem conhecimento (Hagerty, 2016).

Além desses eventos competitivos, os programas no estilo «reality show» também somam ao processo histórico de espetacularização do parkour, ampliando o «show business» (Bourdieu, 1983) da prática. Dentre esses programas, a emissora MTV reuniu atletas da WFPF para compor o elenco de um reality show baseado na modalidade, o Ultimate Parkour Challenge. Um episódio piloto foi ao ar em 2009 e os agentes desse subcampo apresentaram diferentes posicionamentos - a favor e contra -, principalmente devido às lesões sofridas por dois participantes do elenco. Em 2010, nova versão do reality foi ao ar e obteve uma recepção mais favorável pelos agentes (Hagerty, 2016).

No Brasil, os eventos competitivos de parkour/ freerunning foram introduzidos com a realização do Art of Motion em 2011 e, geralmente, são organizados por grupos ou academias nacionais. Em 2014 e 2015, a Academia Tracer (SP) em parceria com a empresa de esporte e comunicação Yescom e a emissora de televisão Rede Globo organizaram o Desafio Urbano de Parkour.

Cabe notar que os participantes do evento em 2014, ficaram restritos ao número de 12 atletas convidados (três estrangeiros e nove brasileiros) do sexo masculino - característica similar às primeiras edições do Art of Motion, em uma franca lógica de reprodução social. Já na edição de 2015, além de oito atletas convidados, foram abertas mais oito vagas ao público do subcampo a serem disputadas em uma etapa classificatória, realizada um dia anterior à data oficial da competição (Yescom, 2015).

$\mathrm{Na}$ edição de 2014, a competição foi desenvolvida em duas etapas: na primeira delas foram classificados seis finalistas de acordo com o tempo de execução completa do percurso de obstáculos naturais (do espaço urbano) e artificiais (montados pela organização); em seguida, os juízes atribuíram notas de 0 a 100 para a qualidade técnica do atleta. Na segunda etapa, por sua vez, os classificados competiram em dupla para o prêmio final, sendo que, além dos aspectos avaliativos anteriores, a cooperação foi acrescida como critério de julgamento a ser avaliada pelos atletas eliminados (Yescom, 2014).

Essa dinâmica foi alterada em 2015 quando atletas competiram em cinco etapas em um percurso com obstáculos artificiais: a primeira etapa consistiu nas eliminatórias, disputadas em pares considerando o tempo individual de cada atleta, sendo o percurso efetivado do início até a metade; a segunda etapa referente ao confronto de oitavas de final, em que seis atletas (três vencedores da edição de 2014 e três atletas estrangeiros convidados) já estavam automaticamente classificados; posteriormente, ocorreram as quartas de final e a semifinal, nas quais os atletas realizaram o percurso da metade até o fim; e, a etapa final em que os atletas efetivaram o percurso completo (Yescom, 2015).

Nessa edição de 2015, foram implementadas penalidades no regulamento do evento (Yescom, 2015). Os atletas seriam desclassificados ao praticarem determinados atos e assim receberem dos árbitros dois cartões amarelo ou um cartão vermelho. O cartão amarelo correspondia aos atos de pisar em áreas externas ao espaço delimitado pela organização, usar as barras de apoio estrutural e manter contato físico não intencional com o concorrente. Já o cartão vermelho implicava em qualquer contato físico intencional como empurrar, puxar e atrapalhar ou em atitudes irresponsáveis como se jogar de lugar alto, manter contato físico não intencional e fazer maluso da estrutura como quebrar algo propositalmente.

Vale ressaltar que a recepção dos agentes do subcampo do parkour a tais edições do Desafio Urbano alternou entra a lógica da «contraposição» e do «consenso». A primeira edição de 2014 foi repudiada por parte dos agentes ao considerarem que a competição distorcia os valores da modalidade a favor do espetáculo. Assim, diferentes grupos de parkour do país compartilharam, até onde foi possível investigar, 16 declarações públicas de «repúdio» ao evento. A primeira declaração foi divulgada pelo Grupo Ibyanga de Sergipe (Figura 2) e a mesma tornou-se modelo para que os demais grupos se pronunciassem.

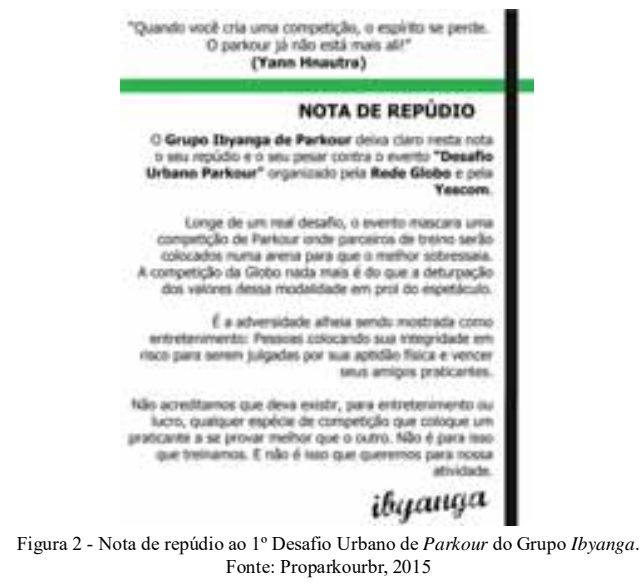

Note-se também que os referidos agentes além de se pronunciarem nas redes sociais virtuais, também se manifestaram de forma pacífica (por meio de cartazes) no local do Desafio Urbano. Todavia, apesar do repúdio por parte da comunidade, o formato de realização do evento se manteve e suas regras não foram alteradas. Já em relação à segunda edição do evento em 2015, observa-se pouca mobilização dos agentes nas ínfimas publicações e debates sobre o mesmo. Isso permite denotar que houve certo «consenso» ou «aceitação» dos praticantes no país a respeito dessa competição (PRÓ PARKOUR, 2015).

Manifestações de contraposição equivalentes, na internet e no local do evento, ocorreram em 2011 com a edição do Art of Motion em São Paulo. Além da comunidade brasileira, parte dos agentes nos Estados Unidos também 
não apoiaram a realização desse evento em seu país, que foi realizado em 2010. Logo, o grupo mais influente dos EUA, a APK, negou apoio ou promoção do evento por considerar que o campeonato nos moldes realizados disseminava uma impressão distorcida da modalidade ao associá-la a determinados comportamentos radicais, a exemplo do uso de bebidas à base de substâncias que alteram o funcionamento normal do corpo. Já em outubro de 2015, com outra edição do mesmo evento no país, a comunidade expôs um posicionamento diferente ao divulgar em sua página online a competição e os praticantes do país que participariam da mesma (American Parkour, 2015).

Esse cenário restituído, por sua vez, sugere que essas tomadas de posição quanto aos eventos de competição de parkour/freeruning configuram uma luta pelo uso legítimo do corpo, mais precisamente, uma disputa entre aqueles que defendem um ideal amadorístico da prática versus aqueles que são afeitos ao ideal profissional. Enquanto o ideal amadorístico ou ortodoxo, marcado pela autonomia, defende o uso hedonista do corpo e considera que a espetacularização contribui para a vulgarização da modalidade, o ideal profissional ou heterodoxo, com ênfase na heteronomia, sustenta, por sua vez, um uso competitivo do corpo com recorrência à logica espetacular. Assim, evidencia-se uma disputa no subcampo do parkour a partir de uma dinâmica conflitiva relacional entre aqueles que visam conservar a estrutura (preservar os princípios autônomos da modalidade) e aqueles que buscam subvertê-la (aderir aos elementos espetaculares e de regulamentação) (Souza \& Marchi-Júnior, 2017). Vale sinalizar que esses conflitos não são apenas exclusivos ao parkour e já foram observados em outras atividades motrizes em vias de esportivização (Souza \& Marchi-Júnior, 2012; Rojo et al., 2017; Badaró, Souza, 2018; Paz, Souza \& Barbosa-Rinaldi, 2018).

Ainda sobre as competições esportivas no parkour, é importante notar que as mesmas implicam regras e normas de conduta, além de uma pedagogia de execução do movimento endossada pela dinâmica interna do subcampo e seus rigorosos regulamentos. Esses eventos competitivos promovem, inclusive, os processos da seleção, da especialização corporal e da instrumentalização - fomentados pelos programas de certificação - propiciando que as técnicas corporais, mas não só elas, uma vez que a organização do espaço físico e os materiais utilizados sofrem mudanças correspondentes, sejam cada vez mais normatizadas e padronizadas (Almeida \& Suassuna, 2010).

$\mathrm{Na}$ esteira desse processo, a espetacularização promove também a atenuação ou perda de características identitárias reveladoras de um potencial habitus genuíno dos agentes, se bem que determinada região do subcampo do parkour pouco se importa com isso, afinal para atingir seus objetivos necessita do reconhecimento esportivo do subcampo e de seus agentes. Em contrapartida, outra região do campo, resistente à esportivização, acredita que as competições, além de romperem com o ethos filosófico do parkour, têm um impacto negativo sobre o praticante em virtude das lesões que são maximizadas mediante a lógica de espetacularização. Além disso, ao assumir esses contornos mercantis, o subcampo dissipa seus elementos constituintes como a centralidade da superação de si mesmo e a não- competitividade com o próximo.

Por outro lado, essa lógica de espetacularização contribuiu não só para a expansão dos movimentos como mais amplamente da filosofia do parkour. Ademais, é importante frisar que muitos praticantes, devido ao desempenho apresentado nesses eventos, têm adquirido reconhecimento, popularidade e, consequentemente, patrocínios. Logo, competir ou «vender» aulas de parkour tornaram-se um meio de subsistência para parte desses profissionais munidos de competência técnica.

Isso que está sendo dito, por seu turno, reporta àquilo que asseverou Bourdieu (1983) ao afirmar que o campo das práticas esportivas é o lugar de lutas que disputam o monopólio de imposição da definição legítima da prática esportiva e da função legítima da atividade. Nesse caso, é possível afirmar que o subcampo do parkour, mediante uma lógica institucional mercantilizada e espetacularizada, está se constituindo como um espaço de lutas ao delimitar a função legítima da prática em virtude dos embates entre amadores e profissionais, entre os que são favoráveis ou resistentes às competições, entre competidores e não competidores, entre quem possui acesso à academia e quem não possui, e assim por diante.

Essa lógica apresentada, evidentemente, não é privilégio do subcampo do parkour e constitui uma lei geral de funcionamento dos diferentes espaços de reprodução cultural na sociedade de consumo, dentre os quais está incluído o campo das práticas esportivas. Além disso, tal como sugerido por Souza (2010), é possível pensar na constituição concreta do campo esportivo não apenas em termos dessas lutas, mas também em relação ao consenso, já que muito dos esportes em seu processo de construção histórico-social foram emprestando às outras e demais modalidades esportivas seus modelos de gestão e gerenciamento. $\mathrm{O}$ parkour, nesse sentido, é mais uma dessas práticas que tem trilhado um percurso histórico semelhante e relacional a outras modalidades esportivas e atividades motrizes (Rojo et al., 2017; Ferreira, Souza \& Marchi-Júnior, 2017; Marchi et al., 2017; Lessa \& Silva, 2017; Delgado \& Gómez, 2018; Paz, Souza \& Barbosa-Rinaldi, 2018; Fortunato et al., 2019) em franco e crescente processo de esportivização, mercantilização e espetacularização na contemporaneidade.

\section{Considerações Finais}

Ao longo do artigo, procuramos analisar o processo de constituição histórica do subcampo esportivo do parkour, levando em conta as dinâmicas de institucionalização e espetacularização da modalidade. Por meio das produções online dos agentes foi possível recuperar alguns elementos estruturantes desse processo e, assim, entender melhor como se deu e o que representou o surgimento das instituições de regulamentação da prática, dos programas de profissionalização e dos eventos competitivos e produções midiáticas que tendencialmente exploraram sua espetacularização.

Foi, inclusive, em virtude desse cenário marcado por uma lógica institucional e espetacular racionalista que se produziram transformações decisivas na estrutura da modalidade e no próprio habitus dos agentes. Em outras 
palavras, essa incursão ao universo do parkour permitiu visualizar uma tendência à exibição, normatização e profissionalização da prática no decorrer de sua estruturação como um dos subcampos emergentes e potencialmente concorrente no interior do campo esportivo.

Pode-se dizer, portanto, que a institucionalização da modalidade frente à apropriação de elementos da lógica esportiva singularizou-se pela expansão de uma série de organizações e academias, além de programas de certificação de instrutores pelos quais foi regulada a distribuição desigual de um capital cultural institucionalizado aos agentes que lutam pelo monopólio do ensino legítimo dessa prática. Por conseguinte, essa lógica crescente de especialização, ao distinguir os profissionais dos amadores, desencadeou uma ruptura decisiva no subcampo e configurou relações de poder mediadas pela obtenção desse capital.

Ressaltamos que essas relações de poder foram se intensificando com o surgimento de eventos competitivos, os quais acentuaram os contornos mercantis e espetaculares do parkour. Essa dinâmica, no entanto, não foi recebida de forma pacífica, afinal, embora tais competições tendessem a favorecer a disseminação da modalidade, parte dos agentes se manifestou contrária à realização dos mesmos. Essas tomadas de posição, por sua vez, remetem à luta em torno dos usos corporais legítimos mediante um jogo de forças entre amadores - que defendem o uso mais hedonista da modalidade e a conservação de sua estrutura inicial - e profissionais - que articulam o seu uso competitivo e mercadológico visando uma transformação dessa estrutura.

Para levar a cabo essas análises, as contribuições teóricas de Bourdieu, em especial aquelas concernentes à leitura do campo esportivo, foram indispensáveis e nos permitiram identificar lutas e resistências, assim como relações de poder imbricadas à estruturação do parkour como uma prática esportiva relativamente «jovem» e que vem incorporando elementos externos que têm ressignificado sua lógica. Por meio dessa abordagem, foi possível verificar também o despertar de uma disputa sobre a legitimidade social da modalidade, mediante uma dialética entre a oferta e demanda dos bens culturais regulada pela apropriação desigual dos capitais cultural e social.

Por fim, compete destacar, a partir das análises acumuladas ao longo do texto, que a lógica espetacular a acomodar a oferta das atividades motrizes na contemporaneidade, sugere que a mercantilização de bens simbólicos e culturais tem imprimido uma direção comum para todas essas práticas em ritmos diferenciados de esportivização, de modo a produzir tensões e introduzir outros capitais sociais e simbólicos nesse universo.

\section{Agradecimentos}

Os autores agradecem à Coordenação de Aperfeiçoamento de Pessoal de Nível Superior (CAPES) pelo suporte financeiro aos bolsistas.

\section{Referências}

Aggerholm, K., \& Larsen, S.H. (2016). Parkour as acrobatics: an existential phenomenological study of movement in parkour. Qualitative Research in sport, exercise and health, 9(1), 69-86.

Almeida, A.J.M., \& Dulce Suassuna, M.F.A. (2010), Práticas corporais, sentidos e significado: uma análise dos jogos dos povos indígenas. Revista Movimento, 16(4), 53-71.

American Parkour (2014). APK College Affiliate Program. Recuperado de http://americanparkour.com/apk-u

American Parkour (2015). Art of Motion in Review. Recuperado de http://americanparkour.com/articles/art-ofmotion-in-review

American Parkour (2020). Women's Community. Recuperado de http://americanparkour.com/women

Art du Deplacement And Parkour Teaching [ADAPT] (2020a). Adapt Qualifications. Recuperado de http:// adaptqualifications.com

Art du Deplacement And Parkour Teaching [ADAPT] (2020b). Coach Certifications, Recuperado de https:// adaptqualifications.com/collections/coach-certifications1

Badaró, L.F., \& Souza, J. (2018). O subcampo do montanhismo como espaço de disputas: interpretações sociológicas a partir da narrativa de Jon Krakauer em «No ar rarefeito». Revista da Alesde, 9, 284-298.

Bourdieu, P. (1983). Como é possível ser esportivo? In Bourdieu, Pierre (Ed.), Questões de sociologia, Rio de Janeiro: Marco Zero, p. 136-153.

Bourdieu, P. (1989). O poder simbólico, Rio de Janeiro: Bertrand Brasil.

Bourdieu, P. (1990), Programa para uma sociologia do esporte. In Bourdieu, P. (Ed.), Coisas ditas. São Paulo: Brasiliense, 1990, p. 207-220.

Chagas, R.R., Rojo, J.R., \& Girardi, V.L. (2015). O processo de esportivização de uma modalidade: o parkour enquanto prática espetacularizada. Revista da Alesde, 5(1), 21-33.

Delgado,A.A., \& Gómez, G.A. (2018). Valores del espectáculo de fútbol en el estadio: un estudio de caso. Retos. Nuevas tendencias en Educación Física, Deporte y Recreación, 33, 96-101.

Fernandes, A.V. (2018). Transpondo muros socioculturais: relações de gênero e empoderamento de mulheres no Parkour. Dissertação de Mestrado, Universidade Estadual de Maringá, Maringá, PR, Brasil.

Fernandes, A.V., \& Galvão, L.K.S. (2016). Parkour e valores morais: ser forte para ser útil. Motrivivência, 28(47), 226240.

Fernández-Río, J., \& Suarez, C. (2014). Feasibility and students' preliminary views on parkour in a group of primary school children. Physical Education and Sport Pedagogy, 21(3), 281-294.

Ferreira, F.D.C., Souza, J., \& Marchi-Júnior, W. (2017). O processo de difusão do kung fu no ocidente: entre o sentido de perda e a inevitabilidade da perda do sentido. Motrivivência, 29(51), 13-27.

Gus, N. (2011). Parkour and the Multitude: Politics of a Dangerous Art. French Cultural Studies, 22(1), 73-85.

Hagerty, C. (2016). A history of competition in parkour 20072015, Recuperado de http://extremesportsx.com/2016/05/ 03/a-history-of-competition-in-parkour-2007-2015

Jubé, C.N. (2019). O Método Natural de Georges Hébert: princípios e primeiras influências (1905 1914). Revista 
Brasileira de Ciências do Esporte, 1-8.

Jubé, C.N., \& Dalben, A. (2017). Amid Progress and Wilderness: Early Reception of Georges Hébert's Naturist Ideas in Brazil During the First Half of the Twentieth Century. The International Journal Of The History Of Sport, 34(14), 1541-1562.

Jubé, C.N., Quitzau, E.A. (2019). Georges Hébert e a legitimação do esporte no Brasil: notas a partir da imprensa (1920-1930). Motrivivência, 31(57), 1-23.

Kidder, J.L. 2017. Parkour and the City: Risk, Masculinity, and Meaning in a Postmodern Sport. New Brunswick: Rutgers University Press.

Lasheras, I.N.,Arruabarrena, O.U., Martos-García, D., Standal, O.F. (2019). Comprensión de la habilidad desde la perspectiva del futuro profesorado de Educación Física. Retos. Nuevas tendencias en Educación Física, Deporte y Recreación, 36, 121-128.

Lebreton, F., Router, G., Héas, S., \& Bodin, D. (2010), «Cultures urbaines et activités physiques et sportiveses: La sportification du parkour et du street golf comme médiation culturelle. Revue Canadienne de Sociologie, 47,293-317.

Lessa, P.R., \& Silva, M.M. (2017). O ciclismo de estrada e a construção de uma cultura nacionalista: um olhar sobre o tour de France. Movimento, 23(1), 407-418.

Leyden-Rotawisky, J. (2013). Parkour, cuerpos que trazan heterotopías urbanas, Revista Colombiana de Antropología, 49(2), 41-61.

Lordêllo, A.F. (2011). Abordagem histórico-crítica do parkour, seu processo de expansão e realidade na cidade de Salvador/BA. Monografia de Especialização, Universidade Federal da Bahia, Salvador, BA, Brasil.

Marchi, K.B., Souza, J., Marchi-Júnior, W., \& Cavichiolli, F. R. (2017). Surf to tow-in - by an analysis of emergency the field «boards sports». Journal of Physical Education, 28(1), 1-11.

Marchi-Júnior, W. (2004), «Sacando» o Voleibol: do amadorismo à espetacularização da modalidade no Brasil. São Paulo: Editora Hucitec.

Murillo, J.C.C. (2020). Prácticas corporales alternativas: parkour, una forma de ser en la ciudad Alternative body practices: parkour, a way of being in the city. Retos. Nuevas tendencias en Educación Física, Deporte y Recreación, 38, 411-416.

Origuela, M.A., \& Silva, C.L. (2012). El Deporte y la Televisión: El papel del profesional de Educación Física. Retos. Nuevas tendencias en Educación Física, Deporte y Recreación, 22, 33-37.

Parkour Generations (2020a). Parkour Generations. Recuperado de http://parkourgenerations.com

Parkour Generations (2020b). Shirley Darlington-Rowat. Recuperado de http://parkourgenerations.com/ ?team=shirley-darlington-rowat

Paz, B., Souza, J., Barbosa-Rinaldi, I.P. (2018). A constituição de um subcampo esportivo: o caso da ginástica rítmica. Movimento, 24(2), 651-664.

Perriére, C., \& Belle, D. (2014). Des origine à la pratique Parkour, Paris, Amphora.

Potter, B.D. Tracing the Landscape: Re-Enchantment, Play, and Spirituality in Parkour. (2019). Religions, 10, 1-11.
Proparkourbr (2015). Manifestações Desafio Urbano de Parkour. Recuperado de https:// proparkourbr.wordpress.com/2015/01/04/manifestos-desafio-urbano-de-parkour

Raymen, T. (2019). The Paradox of Parkour: Conformity, Resistance and Spatial Exclusion. In Raymen, T., \& Smith, O. Deviant Leisure: Criminological Perspectives on Leisure and Harm. Londres: Palgrave Macmillan.

Rius, J. B., \& Flix, X. T. (2019). El juego del cornerball, un pretexto del pasado para crear debate en la educación física del presente. Retos. Nuevas tendencias en Educación Física, Deporte y Recreación, 37, 810-819.

Rojo, J. R., Starepravo, F. A., Mezzadri, F. M., \& Silva, M. M. (2017). Corrida de rua:

reflexões sobre o «universo» da modalidade. Corpoconsciência, 21(3) 82-96.

Souza, J. (2010). O xadrez em xeque: uma análise sociológica da «história esportiva» da modalidade. Dissertação de Mestrado, Universidade Federal do Paraná, Curitiba, PR, Brasil.

Souza, J. (2011). A reflexividade metodológica de Pierre Bourdieu como modelo heurístico para leitura do esporte no Brasil - potencialidade e contribuições. In MarchiJúnior, W. (Ed.). Ensaios em Sociologia do Esporte, São Paulo: Factash Editora. p. 29-53.

Souza, J., \& Marchi-Júnior, W. (2012). Rupturas e tensões no processo de constituição estrutural do subcampo esportivo do xadrez (1900-1960). Revista Brasileira de Ciências do Esporte, 34(3), 557-570.

Souza, J., \& Marchi-Júnior, W. (2017). «Bourdieu e a Sociologia do Esporte: contribuições, abrangência e desdobramentos teóricos. Tempo social, 29, 243-286.

Stramandinoli,A.L. M., Remonte, J.G; Marchetti, P.H. (2012). Parkour: história e conceitos da modalidade. Revista Mackenzie de Educação Física e Esporte, 11(2), 13- 25.

Thibault, V. (2014). Parkour and the art du déplacement: strength, dignity, community. Montréal: Baraka Books.

Úbeda-Colomer, J.M. 'Como una chica': un estudio provocativo sobre estereotipos de género en educación física. (2019). Retos. Nuevas tendencias en Educación Física, Deporte y Recreación, 36, 74-79.

Ugolotti, N.M. Parkour, leisure and neoliberal cityscapes: a twobook review. (2019). Parkour, leisure and neoliberal cityscapes: a twobook review. Leisure Studies, 38(4), 568574.

World Freerun Association (2014). Barclaycard World Freerun Championships. Recuperado de http:// archive.li/3eD8Z

World Freerunning and Parkour Federation [WFPF] (2020a). Lady WFPF. Recuperado de http://www.wfpf.com/ladywfpf

World Freerunning and Parkour Federation [WFPF] (2020b), Coaching Certifications, Recuperado de https:// wfpf.com/parkour-certifications/

Yescom (2014). Regulamento Desafio Urbano de Parkour. Recuperado de http://www.yescom.com.br/ desafiourbano/2014/portugues

Yescom (2015). Regulamento Desafio Urbano de Parkour. Recuperado de http://www.yescom.com.br/ desafiourbano/2015/portugues 